IOS Press

\title{
Reliability and sensitivity of the 6 and 30 second Wingate tests in physically active males and females
}

\author{
Mykolas Kavaliauskas $^{a, *}$ and Shaun M. Phillips ${ }^{\mathrm{b}}$ \\ ${ }^{a}$ School of Life, Sport and Social Sciences, Edinburgh Napier University, Edinburgh, Scotland, UK \\ ${ }^{\mathrm{b}}$ Institute for Sport, Physical Education, and Health Sciences, University of Edinburgh, Edinburgh, Scotland, UK
}

Received 21 January 2016

Accepted 3 May 2016

\begin{abstract}
.
BACKGROUND: Despite widespread use of 6 and 30 second Wingate anaerobic tests (WAnT), performance reliability of these protocols over repeated trials in active males and females has not been determined.

OBJECTIVE: This study assessed the performance reliability and test sensitivity of the $6 \mathrm{~s}$ and $30 \mathrm{~s}$ WAnT.

METHODS: Twenty physically active participants (10 males and 10 females) completed a $6 \mathrm{~s}$ and $30 \mathrm{~s}$ WAnT against $7.5 \%$ body mass resistance on four occasions.

RESULTS: Peak power output (PPO) and mean power output (MPO) did not differ across trials for either gender. Male PPO in both sprint durations demonstrated random variation (standard error of measurement (SEM)) $\leqslant 3.9 \%$ in all between-trials comparisons. For MPO, SEM was $\leqslant 2.9 \%$ in all comparisons. For females, random variation in PPO in both sprint durations was lower in trial 3-4 than earlier pairs of trials. MPO between trials in the $6 \mathrm{~s}$ sprint was variable, with the smallest variation between trials 1-2. For the $30 \mathrm{~s}$ sprint, MPO was more stable across trials. Across all four trials, only MPO in the $30 \mathrm{~s}$ test for males displayed good test sensitivity.

CONCLUSIONS: In conclusion, familiarisation may not be required to establish consistent performance in physically active males or females during the 6 and $30 \mathrm{~s}$ WAnT. Furthermore, general marginal test sensitivity in both tests and genders suggests that results of WAnT in physically active participants should not be used to investigate the genuine effect of an intervention.
\end{abstract}

Keywords: Performance, testing, cycle, sprint, power

\section{Introduction}

Performance reliability is defined as the consistency or reproducibility of a test over repeated trials in the same individuals [11]. Some inherent biological and technical variation in continuous measurements is expected [1]. Therefore, quantifying the degree of such variation is important when assessing the true perfor-

\footnotetext{
${ }^{*}$ Corresponding author: Mykolas Kavaliauskas, School of Life, Sport and Social Sciences, Edinburgh Napier University, 2.B.38, Sighthill Campus, Edinburgh EH11 4BN, Scotland, UK. Tel.: +44 0131455 3381; E-mail: m.kavaliauskas@napier.ac.uk.
}

mance change in research and practice [12]. To help address this, reliability studies should report the degree to which repeated measurements vary for individuals (relative reliability) and monitor changes over time (absolute reliability) [1]. Knowledge of learning or practice effects (defined as a systematic change in scores during performance of a novel exercise) should also be considered for the detection and interpretation of genuine performance changes [19].

The Wingate anaerobic test (WAnT) is the most popular method of assessing anaerobic exercise performance in athletic and general populations [3,25]. A traditional 30 second WAnT has been shown to 
be valid, reliable and sensitive [5]. More recently, 6-, 10-, 20-second WAnT protocols have been proposed as shorter, effective alternatives to the 30 second WAnT $[2,10,19,28]$. However, due to differences in sprint durations, populations and protocols direct comparisons of performance reliability between the studies should not be made.

For example, current knowledge on the performance reliability of cycle sprinting suggests that reliability data from one sprint duration should not be applied to sprints of different durations. Sprint tests of longer duration appear to be more reliable than those of shorter duration, perhaps because independent errors in individual repetitions (defined for cycle tests as individual pedal revolutions) tend to cancel themselves out as more repetitions are completed [12]. A study by Mendez-Villanueva and Bishop [19] assessed reliability of the $6 \mathrm{~s}$ sprint with participants sprinting in a standing position meaning the data cannot be applied when the sprint is conducted in the more common seated position [18]. Furthermore, reliability results may also differ between genders as non-athletic females appear less reliable in measures of power than non-athletic males, possibly due to lower physical activity levels and power output (PO) [12].

Most studies conducted two trials [4,13,19,21,23], but at least one familiarisation trial is recommended for assessment of cycle sprint performance, as there is often a larger performance change between the first two trials than subsequent pairs of trials [12]. This suggests that two trials may not be sufficient to fully evaluate performance reliability or the magnitude of a practice effect.

$6 \mathrm{~s}$ WAnT has recently been shown to be a valid measure of peak power output (PPO) compared with the $30 \mathrm{~s}$ WAnT [10]. However, there is currently no published data investigating the absolute and relative reliability and sensitivity of a group of males and females performing the 6 and $30 \mathrm{~s}$ WAnT over repeated trials.

Therefore, the aim of this study was to investigate the performance reliability and test sensitivity of the 6 and $30 \mathrm{~s}$ WAnT in physically active males and females. It was hypothesised that for both genders performance reliability in both sprint durations would improve following the first two trials and remain stable in subsequent trials, and that males would show better performance reliability than females across all trials.

\section{Materials and methods}

\subsection{Subjects}

Twenty healthy, physically active participants (males, $n=10$, age: $24.2 \pm 4.8$ years, height $181 \pm$ $4 \mathrm{~cm}$, body mass $(\mathrm{BM}): 80.8 \pm 6.9 \mathrm{~kg}$; females, $n=$ 10 , age $22.9 \pm 5.4$ years, height $167 \pm 6 \mathrm{~cm}$, BM 66.8 $\pm 8.9 \mathrm{~kg}$ ) participated in this study. Criteria for participation were to be physically active but not engaged in regular training for a specific sport, and to be inexperienced at cycle ergometer sprinting. Participants were informed of the nature of the investigation, after which they gave written informed consent. The study was approved by the University Research Ethics Committee and conducted in accordance with the Declaration of Helsinki.

\subsection{Testing procedures}

Four trials were completed, each separated by 24 days. Within-participants, all trials were completed at the same time of day. Participants were requested to follow their normal diet for $24 \mathrm{~h}$ prior to the first trial and to record all food and drink consumed. This diet was replicated prior to subsequent trials. Participants were requested to fast for $2 \mathrm{~h}$ prior to exercise, and to refrain from strenuous exercise, alcohol and caffeine consumption for $\geqslant 24 \mathrm{~h}$ before each trial. Adherence to these procedures was verbally confirmed at each trial.

In trial 1, all equipment and procedures were explained to the participant. Height and BM wearing minimal clothing were recorded using a height stadiometer (Seca model 245, Hamburg, Germany) and digital scale (Seca model 708, Hamburg, Germany). The cycle ergometer (Monark Ergomedic 894E, Sweden) was then adjusted to fit the participant, and the seat and handlebar positions were recorded to enable the ergometer to be identically prepared for subsequent trials. A 4 min warm-up was completed against a load of $1 \mathrm{~kg}$, followed by $3 \times 2 \mathrm{~s}$ maximal cycling against a $7.5 \% \mathrm{BM}$ load, interspersed with $45 \mathrm{~s}$ easy cycling [19]. The participant then dismounted the ergometer and sat for $3 \mathrm{~min}$, where any questions about the upcoming test were addressed. The participant then remounted the ergometer and sat stationary with their dominant foot at the 2 o'clock position. A verbal countdown of " $3,2,1$, go" was provided, after which the participant cycled maximally. The $7.5 \%$ $\mathrm{BM}$ resistance was automatically added to the ergometer once cadence reached $110 \mathrm{rpm}$, and the $6 \mathrm{~s}$ sprint 
began. Vigorous verbal encouragement was provided throughout the test. On completion, the participant cycled easily against a $1 \mathrm{~kg}$ resistance for $1 \mathrm{~min}$, then dismounted the ergometer and sat quietly for $15 \mathrm{~min}$.

Following the 15 min recovery period, the participant remounted the ergometer and completed a $30 \mathrm{~s}$ sprint against $7.5 \% \mathrm{BM}$ resistance. The starting procedure was the same as that for the $6 \mathrm{~s}$ sprint, and vigorous verbal encouragement was provided. On completion, the participant cycled easily against a $1 \mathrm{~kg}$ resistance for $3 \mathrm{~min}$, then dismounted the ergometer. Trials 2-4 were the same as trial 1 , with the omission of the equipment introduction and height measurement. Sprint order remained the same for each trial (6 s sprint then 30 s sprint).

Participants were weighed using the same calibrated digital scale before each trial to ensure accurate resistance on the flywheel. Participants were blinded to elapsed time and cadence during sprints, and were not provided with information regarding their performance until they had completed all trials.

\subsection{Measurements}

For each sprint, PPO and MPO were measured. Assessment of performance reliability was the focus of the study, so no additional measurements were made. Other measurements would not have enhanced the quantification of reliability, and may have interfered with participants' preparation and/or performance during the sprints, influencing the reliability data.

\subsection{Data analysis}

Systematic bias in PPO and MPO for each gender was investigated using a two-way repeated measures ANOVA (trial $\times$ sprint duration). A two-way mixed model ANOVA (trial $\times$ gender) compared PPO and MPO across trials and between genders. Bonferroni corrections explored significant main effects. Cohen's $d$ effect sizes were calculated for all significant post-hoc comparisons [7]. Effect sizes $(d)$ were defined as trivial (0-0.19), small (0.20-0.49), medium (0.50$0.79)$ and large $(\geqslant 0.80)$ according to the scale of magnitude proposed by Cohen [7]. Statistical significance was set at $P<0.05$.

Reliability across the four trials was expressed in terms of changes in the mean ( $\mathrm{W} \cdot \mathrm{kg}^{-1}$ and $\%$ change). In addition, relative and absolute reliability indices were calculated using intraclass correlation coefficient (ICC) and standard error of measurement (SEM;
$\mathrm{W} \cdot \mathrm{kg}^{-1}$ and \%), respectively. The smallest worthwhile change (SWC) was determined by multiplying the smallest worthwhile effect of 0.2 (based on Cohen's $d$ effect size) by the between-participant $s$ [9]. This allowed interpretation of the sensitivity of the Wingate tests to detect a real performance change by comparing the SWC and SEM using thresholds from Liow and Hopkins [14]. Briefly, if the SEM is smaller than the SWC, the ability of the test to detect a change is "good"; if the SEM equals the SWC, the test is "satisfactory," and if the SEM is greater than the SWC, the test is "marginal" [9].

\section{Results}

Peak power output and MPO for males and females across all trials in both sprints are in Table 1. For males, there was no significant main effect of trial $\left(F_{3,27}=\right.$ 2.2, $P>0.05)$ and no interaction effect $\left(F_{3,27}=\right.$ $0.54, P>0.05)$. However, there was a significant main effect of sprint duration $\left(F_{1,9}=22.0, P<0.05\right)$. Peak power output in the $6 \mathrm{~s}$ sprint was significantly greater than the $30 \mathrm{~s}$ sprint across all trials $(P<0.05$, $d=1.86,1.53,2.41$, and 1.38 for trials $1-4$, respectively). Similarly, there was no significant main effect of trial $\left(F_{3,27}=2.3, P>0.05\right)$ or interaction $\left(F_{3,27}=\right.$ 1.0, $P>0.05)$ for MPO, but there was a main effect of sprint duration $\left(F_{1,9}=730, P<0.05\right)$, with MPO significantly greater in the $6 \mathrm{~s}$ sprint than the 30 s sprint across all trials $(P<0.05 ; d=12.11$, $15.18,15.44$, and 18.94 for trials $1-4$, respectively). For females, there was no significant main effect of trial $\left(F_{3,27}=0.83, P>0.05\right)$ and no interaction effect $\left(F_{1.97,17.72}=0.47, P>0.05\right)$. However, there was a significant main effect of sprint duration $\left(F_{1,9}=\right.$ $34.5, P<0.05)$. Peak power output in the $6 \mathrm{~s}$ sprint was significantly greater than the $30 \mathrm{~s}$ sprint across all trials $(P<0.05, d=1.50,2.19,2.71$, and 1.80 for trials $1-4$, respectively). There was no significant main effect of trial $\left(F_{3,27}=0.3, P>0.05\right)$ or interaction $\left(F_{1.48,13.32}=1.27, P>0.05\right)$ for MPO. However, there was a main effect of sprint duration $\left(F_{1,9}=\right.$ $110.7, P<0.05)$, with MPO significantly greater in the $6 \mathrm{~s}$ sprint than the $30 \mathrm{~s}$ sprint across all trials $(P<$ $0.05, d=5.83,7.77,6.84$, and 7.14 for trials $1-4$, respectively).

For PPO, there was a significant main effect of gender for the $6 \mathrm{~s}$ sprint $\left(F_{1,9}=42.0, P<0.05\right)$ and the $30 \mathrm{~s}$ sprint $\left(F_{1,9}=43.5, P<0.05\right)$. Peak power output was significantly greater $(P<0.05)$ in the males 
Table 1

Peak power output and mean power output for males and females in all trials for the $6 \mathrm{~s}$ and $30 \mathrm{~s}$ sprints. Data are mean $\pm \mathrm{SD}$

\begin{tabular}{|c|c|c|c|c|}
\hline & Trial 1 & Trial 2 & Trial 3 & Trial 4 \\
\hline \multicolumn{5}{|c|}{$6 \mathrm{~s}$ PPO $\left(\mathrm{W} \cdot \mathrm{kg}^{-1}\right)$} \\
\hline Male & $14.21 \pm 1.64^{* \wedge}$ & $14.29 \pm 1.58^{* \wedge}$ & $14.69 \pm 1.61^{* \wedge}$ & $14.27 \pm 1.53^{* \wedge}$ \\
\hline Female & $10.49 \pm 1.38^{* *}$ & $10.69 \pm 1.52^{* *}$ & $10.94 \pm 2.14^{* *}$ & $10.53 \pm 2.10^{* *}$ \\
\hline \multicolumn{5}{|c|}{$6 \mathrm{~s} \mathrm{MPO}\left(\mathrm{W} \cdot \mathrm{kg}^{-1}\right)$} \\
\hline Male & $12.17 \pm 0.88^{* \wedge}$ & $12.32 \pm 1.02^{* \wedge}$ & $12.51 \pm 1.05^{* \wedge}$ & $12.37 \pm 0.91^{* \wedge}$ \\
\hline Female & $9.43 \pm 1.27^{* *}$ & $9.56 \pm 1.20^{* *}$ & $9.53 \pm 1.65^{* *}$ & $9.31 \pm 1.56^{* *}$ \\
\hline \multicolumn{5}{|c|}{$30 \mathrm{~s}$ PPO $\left(\mathrm{W} \cdot \mathrm{kg}^{-1}\right)$} \\
\hline Male & $13.04 \pm 1.70^{\wedge}$ & $13.39 \pm 1.78^{\wedge}$ & $13.75 \pm 1.57^{\wedge}$ & $13.40 \pm 1.52^{\wedge}$ \\
\hline Female & $9.76 \pm 1.43$ & $9.78 \pm 1.42$ & $9.89 \pm 1.73$ & $9.67 \pm 1.52$ \\
\hline \multicolumn{5}{|c|}{$30 \mathrm{~s} \mathrm{MPO}\left(\mathrm{W} \cdot \mathrm{kg}^{-1}\right)$} \\
\hline Male & $8.84 \pm 0.59^{\wedge}$ & $8.82 \pm 0.61^{\wedge}$ & $8.93 \pm 0.59^{\wedge}$ & $8.89 \pm 0.59^{\wedge}$ \\
\hline Female & $6.93 \pm 0.81$ & $6.80 \pm 0.77$ & $6.89 \pm 0.79$ & $6.88 \pm 0.71$ \\
\hline
\end{tabular}

* Significantly greater than the same trial for the $30 \mathrm{~s}$ sprint (male data); ** Significantly greater than the same trial for the $30 \mathrm{~s}$ sprint (female data); ^ Significantly greater than the corresponding female data.

across all trials for the $6 \mathrm{~s}$ sprint $(d=4.05,2.87,2.11$, and 2.56 for trials $1-4$, respectively) and the $30 \mathrm{~s}$ sprint ( $d=2.54,2.38,2.88$, and 3.58 for trials $1-4$, respectively). For MPO, there was a significant main effect of gender for the $6 \mathrm{~s}$ sprint $\left(F_{1,9}=44.4, P<0.05\right)$ and the $30 \mathrm{~s}$ sprint $\left(F_{1,9}=64.1, P<0.05\right)$. Mean power output was significantly greater $(P<0.05)$ in males across all trials in the $6 \mathrm{~s}$ sprint $(d=3.53,2.71$, 2.41 , and 3.15 for trials $1-4$, respectively) and the 30 s sprint $(d=3.78,3.19,3.26$, and 3.93 for trials $1-4$, respectively).

For males, reliability statistics for each performance variable are presented in Table 2. Random variation in PPO and MPO was consistent across all trial comparisons, with ICCs $\geqslant 0.89$ and SEM $\leqslant 3.9 \%$ in all comparisons. For females, reliability statistics for each performance variable are in Table 3. Random variation for PPO in the 6 and $30 \mathrm{~s}$ sprints was notably lower in trial 3-4 compared with the earlier pairs of trials, suggesting improvement in PPO reliability across trials. Mean power output between trials in the $6 \mathrm{~s}$ sprint was variable, with the smallest variation occurring between trials 1-2. For the $30 \mathrm{~s}$ sprint, MPO was more stable across trials.

For males, the test sensitivity of the Wingate test was rated good for MPO in trials 1-2, and satisfactory for trials 3-4, for the $30 \mathrm{~s}$ test. For all other pairwise comparisons, test sensitivity was marginal. For females, test sensitivity was good for PPO between trials 3-4 in the 6 s test, and for MPO between trials 23 in the 30 s test. Test sensitivity was marginal for all other pairwise comparisons. When test sensitivity was assessed across all four trials, only MPO in the $30 \mathrm{~s}$ Wingate test for males displayed good test sensitivity (Tables 2 and 3).

\section{Discussion}

There was no clear and consistent difference in performance reliability between trials 1-2 and subsequent pairs of trials across sprints for either gender. Therefore, the first hypothesis is rejected. Males demonstrated smaller random variation in performance across trials in both sprint durations, therefore the second hypothesis is accepted. However, the sensitivity of both tests to detect the SWC was generally marginal for both genders.

There were no significant changes in PPO or MPO across all trials for both sprint durations in males and females (Table 1). In contrast, previous studies reported significant increases in PPO and MPO between trials 1-2 [4,19,26]. However, Mendez-Villanueva and Bishop [19] assessed reliability of the $6 \mathrm{~s}$ Wingate performed in a standing position, and Secrest et al. [26] recruited a small female sample $(n=5)$ that would have limited the veracity of the statistical analyses. Other work has reported no significant practice effects for cycle sprints lasting $\sim 5-30 \mathrm{~s}[9,13,21]$, indicating that familiarisation is not always required for achievement of stable performance. Performance reliability can be influenced by many factors including training status, time between trials, ergometer quality, and participantspecific characteristics [12], which may help to explain conflicting findings regarding the presence of a practice effect.

No significant difference in PPO or MPO across trials for females appears to refute the suggestion that females may be less reliable than males [12]. However, females demonstrated a notably lower random variation for PPO in trials 3-4 of the 6 and $30 \mathrm{~s}$ sprints. Therefore, it may be useful to familiarise females to Wingate testing if the aim is to detect genuine mean 
Table 2

Pairwise reliability and smallest worthwhile change for peak power output and mean power output during the 6 and $30 \mathrm{~s}$ sprints for the male participants

\begin{tabular}{|c|c|c|c|c|c|c|c|}
\hline & Trial & $\begin{array}{l}\Delta \text { Mean } \\
\left(\mathrm{W} \cdot \mathrm{kg}^{-1}\right)\end{array}$ & $\Delta$ Mean $(\%)$ & ICC & $\begin{array}{c}\text { SEM } \\
\left(\mathrm{W} \cdot \mathrm{kg}^{-1}\right)\end{array}$ & SEM (\%) & $\begin{array}{c}\mathrm{SWC} \\
\left(\mathrm{W} \cdot \mathrm{kg}^{-1}\right)\end{array}$ \\
\hline \multirow[t]{4}{*}{$6 \mathrm{~s} \mathrm{PPO}$} & 1 to 2 & $\begin{array}{l}0.08 \\
(-0.45 \text { to } 0.62)\end{array}$ & $\begin{array}{l}0.75 \\
(-2.57 \text { to } 4.07)\end{array}$ & $0.92(0.71$ to 0.98$)$ & \pm 0.53 (0.37 to 0.97$)$ & 3.9 (2.6 to 7.2$)$ & 0.32 \\
\hline & 2 to 3 & $\begin{array}{l}0.39 \\
(-0.04 \text { to } 0.82)\end{array}$ & $\begin{array}{l}2.86 \\
(0.24 \text { to } 5.48)\end{array}$ & 0.95 (0.80 to 0.99$)$ & $\pm 0.43(0.29$ to 0.78$)$ & $3.0(2.0$ to 5.5$)$ & 0.32 \\
\hline & 3 to 4 & $\begin{array}{l}-0.42 \\
(-0.94 \text { to } 0.11)\end{array}$ & $\begin{array}{l}-2.69 \\
(-5.70 \text { to } 0.32)\end{array}$ & $0.92(0.70$ to 0.98$)$ & $\pm 0.52(0.36$ to 0.95$)$ & $3.6(2.5$ to 6.6$)$ & 0.31 \\
\hline & All Trials & $\begin{array}{l}0.02 \\
(-0.48 \text { to } 0.52)\end{array}$ & $\begin{array}{l}0.31 \\
(-3.13 \text { to } 3.75)\end{array}$ & 0.93 (0.81 to 0.98$)$ & \pm 0.49 (0.38 to 0.71$)$ & $3.5(2.7$ to 5.0$)$ & 0.32 \\
\hline \multirow[t]{4}{*}{$6 \mathrm{~s} \mathrm{MPO}$} & 1 to 2 & $\begin{array}{l}0.15 \\
(-0.13 \text { to } 0.43)\end{array}$ & $\begin{array}{l}1.22 \\
(-0.84 \text { to } 3.28)\end{array}$ & 0.94 (0.76 to 0.98$)$ & $\pm 0.28(0.19$ to 0.51$)$ & 2.4 (1.6 to 4.4$)$ & 0.19 \\
\hline & 2 to 3 & $\begin{array}{l}0.19 \\
(-0.12 \text { to } 0.49)\end{array}$ & $\begin{array}{l}1.55 \\
(-0.63 \text { to } 3.73)\end{array}$ & $0.94(0.77$ to 0.98$)$ & $\pm 0.30(0.21$ to 0.55$)$ & 2.5 (1.7 to 4.6$)$ & 0.21 \\
\hline & 3 to 4 & $\begin{array}{l}-0.14 \\
(-0.50 \text { to } 0.23)\end{array}$ & $\begin{array}{l}-0.93 \\
(-3.32 \text { to } 1.46)\end{array}$ & $0.89(0.63$ to 0.97$)$ & $\pm 0.36(0.25$ to 0.66$)$ & $2.9(2.0$ to 5.3$)$ & 0.20 \\
\hline & All Trials & $\begin{array}{l}0.07 \\
(-0.24 \text { to } 0.38)\end{array}$ & $\begin{array}{l}0.61 \\
(-1.94 \text { to } 3.16)\end{array}$ & $0.92(0.79$ to 0.98$)$ & $\pm 0.32(0.24$ to 0.45$)$ & $2.6(2.0$ to 3.7$)$ & 0.20 \\
\hline \multirow[t]{4}{*}{$30 \mathrm{~s}$ PPO } & 1 to 2 & $\begin{array}{l}0.34 \\
(-0.19 \text { to } 0.87)\end{array}$ & $\begin{array}{l}2.71 \\
(-0.44 \text { to } 5.86)\end{array}$ & 0.93 (0.75 to 0.98$)$ & $\pm 0.52(0.36$ to 0.96$)$ & 3.7 (2.5 to 6.8$)$ & 0.35 \\
\hline & 2 to 3 & $\begin{array}{l}0.36 \\
(-0.06 \text { to } 0.78)\end{array}$ & $\begin{array}{l}3.03 \\
(0.23 \text { to } 5.83)\end{array}$ & $0.96(0.83$ to 0.99$)$ & $\pm 0.41(0.28$ to 0.75$)$ & $3.2(2.2$ to 5.9$)$ & 0.34 \\
\hline & 3 to 4 & $\begin{array}{l}-0.34 \\
(-0.80 \text { to } 0.11)\end{array}$ & $\begin{array}{l}-2.40 \\
(-5.21 \text { to } 0.41)\end{array}$ & $0.94(0.77$ to 0.98$)$ & $\pm 0.45(0.31$ to 0.82$)$ & $3.4(2.3$ to 6.3$)$ & 0.31 \\
\hline & All Trials & $\begin{array}{l}0.12 \\
(-0.34 \text { to } 0.58)\end{array}$ & $\begin{array}{l}1.11 \\
(-2.26 \text { to } 4.48)\end{array}$ & 0.94 (0.84 to 0.98$)$ & \pm 0.46 (0.36 to 0.66$)$ & $3.4(2.6$ to 4.9$)$ & 0.33 \\
\hline \multirow[t]{4}{*}{$30 \mathrm{~s}$ MPO } & 1 to 2 & $\begin{array}{l}-0.02 \\
(-0.10 \text { to } 0.06)\end{array}$ & $\begin{array}{l}-0.25 \\
(-1.07 \text { to } 0.57)\end{array}$ & $0.99(0.95$ to 1.00$)$ & $\pm 0.08(0.06$ to 0.15$)$ & $0.9(0.6$ to 1.7$)$ & $0.12 \dagger$ \\
\hline & 2 to 3 & $\begin{array}{l}0.11 \\
(-0.01 \text { to } 0.24)\end{array}$ & $\begin{array}{l}1.33 \\
(0.06 \text { to } 2.60)\end{array}$ & 0.97 (0.87 to 0.99$)$ & $\pm 0.13(0.09$ to 0.23$)$ & $1.4(1.0$ to 2.7$)$ & 0.12 \\
\hline & 3 to 4 & $\begin{array}{l}-0.05 \\
(-0.17 \text { to } 0.07)\end{array}$ & $\begin{array}{l}-0.53 \\
(-1.70 \text { to } 0.64)\end{array}$ & $0.97(0.89$ to 0.99$)$ & $\pm 0.12(0.08$ to 0.21$)$ & $1.4(0.9$ to 2.5$)$ & $0.12 \dagger$ \\
\hline & All Trials & $\begin{array}{l}0.01 \\
(-0.10 \text { to } 0.12)\end{array}$ & $\begin{array}{l}0.18 \\
(-1.08 \text { to } 1.44)\end{array}$ & $0.97(0.93$ to 0.99$)$ & \pm 0.11 (0.08 to 0.16$)$ & $1.3(1.0$ to 1.18$)$ & $0.12 \dagger$ \\
\hline
\end{tabular}

ICC $=$ intraclass correlation coefficient; SEM = standard error of measurement; SWC $=$ smallest worthwhile change; $\nmid$ indicates that test sensitivity is good $(\mathrm{SEM}<\mathrm{SWC})$ or satisfactory $(\mathrm{SEM}=\mathrm{SWC})$; Values in parentheses are $95 \%$ confidence limits.

changes in PPO between trials. Females also demonstrated more between-trials error in PO measures than males.

Participants in the current study recorded significantly greater PPO in the $6 \mathrm{~s}$ sprint than the $30 \mathrm{~s}$ sprint across all trials (Table 1). Lower PPO in the 30 s sprints was probably not due to residual fatigue from having undertaken the $6 \mathrm{~s}$ sprint $\sim 15$ min earlier, as pilot work confirmed that 15 minute rest was sufficient to recover from the $6 \mathrm{~s}$ sprint before performing the $30 \mathrm{~s}$ sprint. Lower PPO in the $30 \mathrm{~s}$ trials may be evidence of a pacing strategy. Previous work has shown dampened PO and reduced fatigue index in the first $15 \mathrm{~s}$ of a $30 \mathrm{~s}$ cycle sprint compared with a 15 s sprint [27], suggesting that people only exert their true maximal cycling power when test duration is $<30 \mathrm{~s}$ [15]. The current study appears to be the first to demonstrate significant differences in PPO between sprint durations of 6 and $30 \mathrm{~s}$.
Test sensitivity of both sprint durations was generally marginal (Tables 2 and 3). Athletic participants appear to be more reliable in measures of PO than non-athletic participants [12]. Participants in the current study were physically active, but not training for a specific sport or experienced at cycle sprinting. Therefore, these participants may have demonstrated sufficiently large within-participant performance variation that, while not affecting actual PO measures across trials at the group mean level, did lead to larger withinparticipant variability (SEM), thereby impacting on test sensitivity. It would have been interesting to investigate this further by replicating the analysis of McLellan et al. [17] and splitting participants into "high variability" and "low variability" cohorts. Unfortunately, sample sizes were not sufficient to take this approach.

Males recorded significantly greater PPO and MPO than females across all trials for both sprint durations (Table 1). This finding was expected, as it has been 
Table 3

Pairwise reliability and smallest worthwhile change for peak power output and mean power output during the 6 and $30 \mathrm{~s}$ sprints for the female participants

\begin{tabular}{|c|c|c|c|c|c|c|c|}
\hline & Trial & $\begin{array}{l}\Delta \text { Mean } \\
\left(\mathrm{W} \cdot \mathrm{kg}^{-1}\right)\end{array}$ & $\Delta$ Mean $(\%)$ & ICC & $\begin{array}{c}\text { SEM } \\
\left(\mathrm{W} \cdot \mathrm{kg}^{-1}\right)\end{array}$ & SEM (\%) & $\begin{array}{c}\mathrm{SWC} \\
\left(\mathrm{W} \cdot \mathrm{kg}^{-1}\right)\end{array}$ \\
\hline \multirow[t]{4}{*}{$6 \mathrm{~s} \mathrm{PPO}$} & 1 to 2 & $\begin{array}{l}0.20 \\
(-0.40 \text { to } 0.80)\end{array}$ & $\begin{array}{l}1.97 \\
(-3.2 \text { to } 7.14)\end{array}$ & 0.87 (0.56 to 0.97$)$ & $\pm 0.59(0.41$ to 1.09$)$ & $6.0(4.1$ to 11.2$)$ & 0.29 \\
\hline & 2 to 3 & $\begin{array}{l}0.26 \\
(-0.30 \text { to } 0.81)\end{array}$ & $\begin{array}{l}1.76 \\
(-2.63 \text { to } 6.15)\end{array}$ & 0.93 (0.76 to 0.98$)$ & $\pm 0.55(0.38$ to 1.01$)$ & $5.1(3.5$ to 9.5$)$ & 0.37 \\
\hline & 3 to 4 & $\begin{array}{l}-0.42 \\
(-0.82 \text { to }-0.02)\end{array}$ & $\begin{array}{l}-3.76 \\
(-7.06 \text { to }-0.46)\end{array}$ & $0.97(0.90$ to 0.99$)$ & $\pm 0.40(0.27$ to 0.73$)$ & $4.1(2.8$ to 7.6$)$ & $0.42 \dagger$ \\
\hline & All Trials & $\begin{array}{l}0.01 \\
(-0.51 \text { to } 0.53)\end{array}$ & $\begin{array}{l}-0.01 \\
(-4.96 \text { to } 4.94)\end{array}$ & 0.94 (0.84 to 0.98$)$ & $\pm 0.52(0.40$ to 0.75$)$ & $5.1(3.9$ to 7.4$)$ & 0.36 \\
\hline \multirow[t]{4}{*}{$6 \mathrm{~s} \mathrm{MPO}$} & 1 to 2 & $\begin{array}{l}0.14 \\
(-0.12 \text { to } 0.40)\end{array}$ & $\begin{array}{l}1.63 \\
(-0.69 \text { to } 3.95)\end{array}$ & 0.97 (0.88 to 0.99$)$ & $\pm 0.26(0.18$ to 0.47$)$ & $2.7(1.8$ to 4.9$)$ & 0.25 \\
\hline & 2 to 3 & $\begin{array}{l}-0.04 \\
(-0.46 \text { to } 0.39)\end{array}$ & $\begin{array}{l}-0.90 \\
(-5.02 \text { to } 3.22)\end{array}$ & $0.94(0.77$ to 0.98$)$ & $\pm 0.42(0.29$ to 0.77$)$ & 5.0 (3.4 to 9.2$)$ & 0.29 \\
\hline & 3 to 4 & $\begin{array}{l}-0.21 \\
(-0.55 \text { to } 0.13)\end{array}$ & $\begin{array}{l}-2.03 \\
(-5.45 \text { to } 1.39)\end{array}$ & 0.97 (0.88 to 0.99$)$ & $\pm 0.34(0.23$ to 0.61$)$ & 4.1 (2.8 to 7.6$)$ & 0.32 \\
\hline & All Trials & $\begin{array}{l}-0.04 \\
(-0.38 \text { to } 0.30)\end{array}$ & $\begin{array}{l}-0.43 \\
(-4.23 \text { to } 3.37)\end{array}$ & $0.96(0.89$ to 0.99$)$ & $\pm 0.35(0.27$ to 0.49$)$ & $4.0(3.1$ to 5.8$)$ & 0.29 \\
\hline \multirow[t]{4}{*}{$30 \mathrm{~s}$ PPO } & 1 to 2 & $\begin{array}{l}0.02 \\
(-0.53 \text { to } 0.58)\end{array}$ & $\begin{array}{l}0.63 \\
(-4.08 \text { to } 5.34)\end{array}$ & 0.89 (0.61 to 0.97$)$ & $\pm 0.55(0.38$ to 1.00$)$ & 5.7 (3.9 to 10.6$)$ & 0.29 \\
\hline & 2 to 3 & $\begin{array}{l}0.10 \\
(-0.51 \text { to } 0.72)\end{array}$ & $\begin{array}{l}0.89 \\
(-4.68 \text { to } 6.46)\end{array}$ & 0.88 (0.60 to 0.97$)$ & $\pm 0.61(0.42$ to 1.12$)$ & $6.5(4.4$ to 12.2$)$ & 0.32 \\
\hline & 3 to 4 & $\begin{array}{l}-0.22 \\
(-0.61 \text { to } 0.17)\end{array}$ & $\begin{array}{l}-1.77 \\
(-5.19 \text { to } 1.65)\end{array}$ & $0.96(0.84$ to 0.99$)$ & $\pm 0.39(0.27$ to 0.70$)$ & $4.1(2.8$ to 7.5$)$ & 0.33 \\
\hline & All Trials & $\begin{array}{l}-0.03 \\
(-0.55 \text { to } 0.49)\end{array}$ & $\begin{array}{l}-0.08 \\
(-5.36 \text { to } 5.20)\end{array}$ & 0.91 (0.78 to 0.97$)$ & $\pm 0.52(0.40$ to 0.75$)$ & $5.5(4.2$ to 8.0$)$ & 0.31 \\
\hline \multirow[t]{4}{*}{$30 \mathrm{~s}$ MPO } & 1 to 2 & $\begin{array}{l}-0.12 \\
(-0.34 \text { to } 0.09)\end{array}$ & $\begin{array}{l}-1.67 \\
(-4.27 \text { to } 0.93)\end{array}$ & $0.95(0.80$ to 0.99$)$ & \pm 0.21 (0.15 to 0.39$)$ & $3.1(2.1$ to 5.7$)$ & 0.16 \\
\hline & 2 to 3 & $\begin{array}{l}0.09 \\
(-0.05 \text { to } 0.22)\end{array}$ & $\begin{array}{l}1.25 \\
(-0.47 \text { to } 2.97)\end{array}$ & $0.98(0.92$ to 0.99$)$ & \pm 0.13 (0.09 to 0.24$)$ & 2.0 (1.3 to 3.6$)$ & $0.16 \dagger$ \\
\hline & 3 to 4 & $\begin{array}{l}-0.01 \\
(-0.18 \text { to } 0.16)\end{array}$ & $\begin{array}{l}0.07 \\
(-2.17 \text { to } 2.31)\end{array}$ & $0.96(0.86$ to 0.99$)$ & \pm 0.17 (0.12 to 0.31$)$ & $2.6(1.8$ to 4.7$)$ & 0.15 \\
\hline & All Trials & $\begin{array}{l}-0.02 \\
(-0.19 \text { to } 0.15)\end{array}$ & $\begin{array}{l}-0.12 \\
(-2.64 \text { to } 2.40)\end{array}$ & $0.96(0.90$ to 0.99$)$ & \pm 0.17 (0.13 to 0.25$)$ & 2.6 (2.0 to 3.7$)$ & 0.16 \\
\hline
\end{tabular}

ICC $=$ intraclass correlation coefficient; SEM = standard error of measurement; SWC = smallest worthwhile change; Values in parentheses are $95 \%$ confidence limits.

consistently demonstrated that males produce significantly greater absolute and BM-relative PPO and MPO than females during Wingate tests [8,22]. While scaling PO to other anthropometric values, such as lean $\mathrm{BM}$, can significantly reduce or negate this gender difference [24], the purpose of the current study was not to evaluate gender differences in PO. Therefore, additional scaling was not undertaken.

From a practical standpoint, no significant difference in PPO or MPO across trials for the 6 and $30 \mathrm{~s}$ Wingate tests in males and females suggests that researchers or practitioners using these tests to evaluate performance may not need to employ a familiarisation to control for practice effects. However, the mostly marginal test sensitivity in both sprint durations for both genders highlights another important practical application. Using a physically active sample unfamiliar with cycle sprinting to assess a performance intervention using the Wingate 6 or $30 \mathrm{~s}$ test may not provide sufficient sensitivity to quantify the ability of the intervention to make a worthwhile change. Therefore, if attempting to judge the potential use of an intervention in a particular population, for example trained athletes, it is important to move beyond convenience sampling to recruit participants that reflect as closely as possible the population that the intervention aims to target. Failure to do so may result in the intervention being incorrectly discarded due to lack of efficacy. If the recruited sample does not adequately reflect the target population, caution should be used when extrapolating results of interventions that use the 6 or $30 \mathrm{~s}$ Wingate test as the performance measure.

One potential limitation of this study is that menstrual cycle stage was not documented, which may have affected the results. However, the influence of the menstrual cycle on PO in females is contentious and evidence suggests that menstrual cycle staging has no significant effect on cycle sprint performance $[6,16$, 
20]. Additionally, completion of the 6 and $30 \mathrm{~s}$ sprints on separate days would have allowed the order of the sprints to be randomised. Finally, time of day of testing was not consistent between-subjects for logistical reasons; however, it was consistent within-subjects.

\section{Conclusion}

In conclusion, no significant difference in PPO or MPO was observed across four trials of a 6 and $30 \mathrm{~s}$ Wingate test in physically active males and females, indicating that familiarisation may not be required to establish consistent performance. However, the lower random variation in PPO between the final two trials for both sprint durations in females suggests familiarisation may be useful for females if the goal of testing is to detect genuine mean changes in PPO. In this physically active, non-cycle sprint habituated sample, the sensitivity of the 6 and $30 \mathrm{~s}$ Wingate tests to detect smallest worthwhile changes in PPO and MPO was generally marginal.

\section{Conflict of interest}

No funding was received for this study. The authors have no conflict of interest and will not benefit, financially or otherwise, by the publication of this work.

\section{References}

[1] G. Atkinson and A.M. Nevill, Statistical methods for assessing measurement error (reliability) in variables relevant to sports medicine, Sports Med 26(4) (1998), 217-238.

[2] A. Attia, Y. Hachana, H. Chaabène, A. Gaddour, Z. Neji, J.R. Shephard and M.S. Chelly, Reliability and validity of a 20-s alternative to the Wingate anaerobic test in team sport male athletes, PLoS One 9(12) (2014).

[3] A.R. Aziz and T.K. Chuan, Correlation between tests of running repeated sprint ability and anaerobic capacity by Wingate cycling in multi-sprint sports athletes, Int J Appl Sports Sci 16 (2004), 14-22.

[4] J.P. Barfield, P.D. Sells, A.D. Rowe and K. Hannigan-Downs, Practice effect of the Wingate anaerobic test, $J$ Strength Cond Res 16 (2002), 472-473.

[5] O.R. Bar-Or, The Wingate anaerobic test: an update on methodology, reliability and validity, Sports Med 4 (1987), 381-394.

[6] B. Bushman, G. Masterton and J. Nelsen, Anaerobic power performance and the menstrual cycle: eumenorrheic and oral contraceptive users. J Sports Med Phys Fitness 46(1) (2006), 132-137.

[7] J. Cohen, A power primer, Psychol Bull 112(1) (1992), 155159.
[8] A. Gratas-Delamarche, R. Le Cam, P. Delamarche, M. Monnier and $\mathrm{H}$. Koubi, Lactate and catecholamine responses in male and female sprinters during a Wingate test, Eur J Appl Physiol 68 (1994), 362-366.

[9] Y. Hachana, A. Attia, S. Nassib, J.R. Shephard and M.S. Chelly, Test-retest reliability, criterion-related validity, and minimal detectable change of score on an abbreviated Wingate test for field sport participants, J Strength Cond Res 26 (2012), 1324-1330.

[10] P. Herbert, N. Sculthorpe, J.S. Baker and F.M. Grace, Validation of a six second cycle test for the determination of peak power output, Res Sports Med 23(2) (2015), 115-125.

[11] W.G. Hopkins, Measures of reliability in sports medicine, Sports Med 30(1) (2000), 1-15.

[12] W.G. Hopkins, E.J. Schabort and J.A. Hawley, Reliability of power in physical performance tests, Sports Med 31 (2001), 211-234.

[13] H. Jaafar, M. Rouis, L. Coudrat, E. Attiogbé, H. Vandewalle and T. Driss, Effects of load on Wingate test performances and reliability, J Strength Cond Res 28 (2014), 3462-3468.

[14] D.K. Liow and W.G. Hopkins, Velocity specificity of weight training for kayak sprint performance, Med Sci Sports Exerc 35 (2003), 1232-1237.

[15] S.M. Marcora and W. Staiano, The limit to exercise tolerance in humans: mind over muscle? Eur J Appl Physiol 109 (2010), 763-770.

[16] G. Masterton, The impact of menstrual phases on anaerobic power performance in collegiate women, $J$ Strength Cond Res 13 (1999), 325-329.

[17] T.M. McLellan, S.S. Cheung and I. Jacobs, Variability of time to exhaustion during submaximal exercise, Can J Appl Physiol 20 (1995), 39-51.

[18] J.R. McLester, J.M. Green and J.L. Chouinard, Effects of standing vs. seated posture on repeated Wingate performance, J Strength Cond Res 18 (2004), 816-820.

[19] A. Mendez-Villanueva and D. Bishop, Reproducibility of a 6-s maximal cycling sprint test, J Sci Med Sport 10 (2007), 323-326.

[20] C.M. Miskec, J.A. Potteiger, K.J. Nau and C.J. Zebas, Do varying environmental and menstrual cycle conditions affect anaerobic power output in female athletes, $J$ Strength Cond Res 11 (1997), 219-223.

[21] R.C. Nicklin, H.S. O'Bryant, T.M. Zehnbauer and A.M. Collins, A computerized method for assessing anaerobic power and work capacity using maximal cycle ergometry, $J$ Strength Cond Res 4 (1990), 135-140.

[22] P. Nikolaidis, Gender differences in anaerobic power in physical education and sport science students, J Phys Ed Sport $\mathbf{2 4}$ (2009), 1-5

[23] J.F. Patton, M.M. Murphy and A.F. Frederick, Maximal power outputs during the Wingate anaerobic test, Int J Sports Med 6 (1985), 82-85.

[24] J. Perez-Gomez, G.V. Rodriguez, I. Ara, H. Olmedillas, J. Chavarren, J.J. Gonzalez-Henriquez, C. Dorado and J.A.L. Calbet, Role of muscle mass on sprint performance: gender differences? Eur J Appl Physiol 102 (2008), 685-694.

[25] R. Ramírez-Vélez, C.A. López-Albán, D.R. La RottaVillamizar, J.A. Romero-García, A.M. Alonso-Martinez and M. Izquierdo, Wingate anaerobic test percentile norms in Colombian healthy adults, J Strength Cond Res 30 (2016), 217-225.

[26] J.R. Secrest, K. Louw, E.J. Jones and T.M. Whitehead, Establishing the Learned Effect of Repeated Wingate Anaerobic Tests, Int J Exer Sci: Conference Proceedings 2 (2013), 24. 
[27] A.L. Wittekind, D. Micklewright and R. Beneke, Teleoanticipation in all-out short-duration cycling, Br J Sports Med $\mathbf{4 5}$ (2009), 114-119.
[28] A. Zając, R. Jarza̧bek and Z. Waśkiewicz, The diagnostic value of the 10- and 30-second Wingate test for competitive athletes, J Strength Cond Res 13 (1999), 16-19. 